\title{
Controlling Hypertension: A Cost-Effective Model
}

\author{
Andrea Foote and John C Erfurt \\ Worker Health Program, Institute of Labor and Industrial Relations. The University of \\ Michigan, 401 Fourth Street, Ann Arbor, Michigan 48103
}

\begin{abstract}
A model system for controlling hypertension that was developed and tested in three industrial settings and three community settings is described. Data from these six projects are shown, indicating the success of the system at reaching the target population, referring people with uncontrolted high blood pressure to physicians for diagnosis and treatment, and carrying out routine follow-up and inducement activities to assist people in maintaining adequate blood pressure control. More than 1300 people were identified by these projects as having uncontrolled hypertension. After an average of 13 months of follow-up, $87 \%$ had been successfully referred to a physician; of the group successfully referred, $88 \%$ had entered treatment for hypertension, and of those under treatment, $80 \%$ had shown progress toward successful blood pressure control. The cost of the system is detailed and compared with estimates of the cost incurred by an industrial firm due to cardiovascular disease. It is argued that employers who pay for any substantial health benefit plan will ultimately save money by implementing a blood pressure control program modeled after this system. The system is also effective in community settings: however, the cost-benefit figures for programs in such settings are more difficult to estimate.
\end{abstract}

\section{THE PROBLEM}

Hypertension is well known as one of the leading risk factors for the number one killer in the United States, cardiovascular disease $(3,10,11)$. The data in Fig. 1, based on the 1959 Build and Blood Pressure Study, indicate large increases in the risk of mortality with relatively small increments in blood pressure, either systolic or diastolic (12).

In recent years there has been substantial progress in our ability to treat hypertension. Many new medications have been tested and found effective at reducing blood pressure to normal levels, and the Veterans Administration studies have demonstrated the reduction in risk of cardiovascular events that results from controlling high blood pressure in this way $(16,17)$.

As the new medications have come into common usage, however, it has become clear that many patients drop out of treatment, and that a great many other people with elevated blood pressure are not being diagnosed.

Both problems result from the asymptomatic nature of the disease. Our health care delivery system is not organized to handle asymptomatic diseases; health care is triggered primarily when a person feels sick and visits a doctor. As a result, while hypertension is now largely controllable, it remains largely uncontrolled.

\section{REVIEW OF PREVIOUS WORK}

In response to this situation, several different strategies have been developed. The National Heart and Lung Institute of DHEW adopted a broad public education strategy implemented by the National High Blood Pressure Education Program. This program has allocated a large portion of its resources to a mass media campaign to alert people regarding the dangers of high blood pressure. A prelimi- 


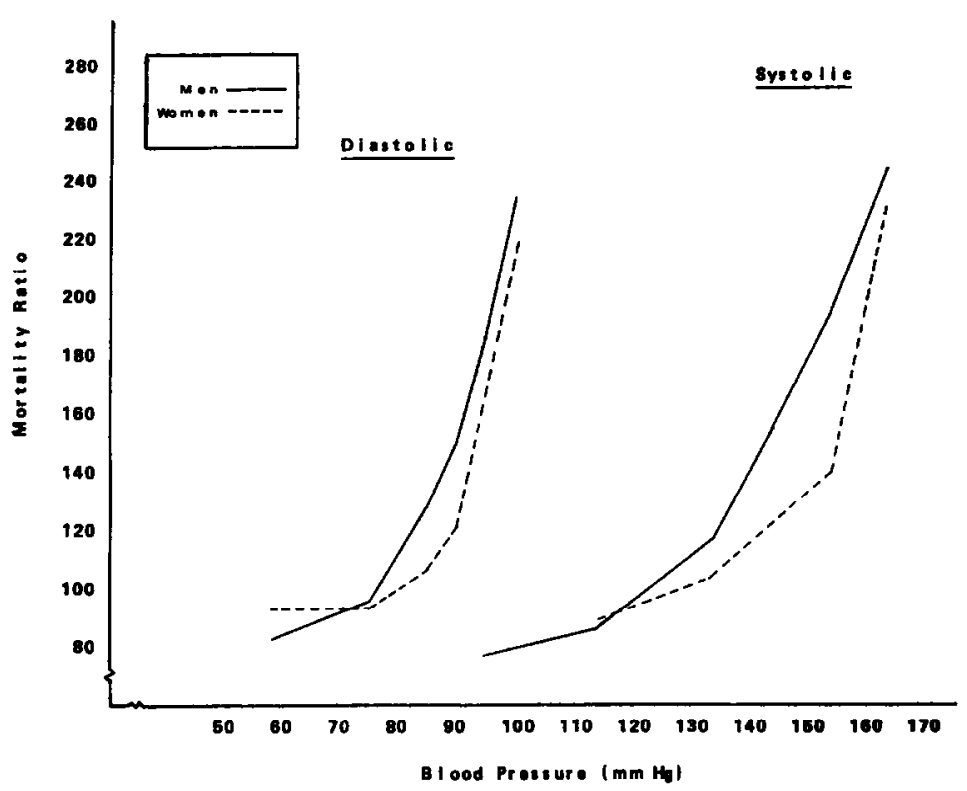

FIG. 1. Mortality by blood pressure levels. Mortality ratio is the ratio of actual to expected mortality (mortality among standard risks $=100$ ). Data are based on a study of 26 large life insurance companies, covering some four million policies issued to men and women from 1935 to 1953 . Reproduced with permission from data reported by Lew (12).

nary estimate of the effectiveness of this strategy in the Detroit area may be made by comparing baseline data gathered prior to implementation of the program with data gathered since the program began.

Table 1 shows two sets of baseline data. The first consists of estimates of the adequacy of blood pressure control in the United States made by the National Heart and Lung Institute based on studies carried out in the 1960's. The second set provides estimates of the adequacy of blood pressure control in the Detroit area (7) made by The University of Michigan's Program for Urban Health Research on the basis of 1968-69 data (8). The two sets of figures are quite similar.

Table 1 also shows recent estimates of the adequacy of blood pressure control in the Detroit area, based on seven projects undertaken since 1974. These projects do not comprise a random sample of the Detroit-area population, but they do include substantial representation from all subgroups based on age, sex, and race (excluding children). The NHLI educational campaign was well underway before any of these projects was begun.

The data in Table 1 show the awareness and treatment status, at the time of initial screening, for the people in each group who were found to be hypertensive (that is, who had blood pressure (BP) elevations above $160 / 95 \mathrm{~mm} \mathrm{Hg}$ or were under treatment for hypertension). The differences across the seven recent projects can largely be attributed to differential composition by sex and age, with women and older people more likely to be under adequate treatment (BP below $140 / 90 \mathrm{~mm} \mathrm{Hg}$ ) than men and younger people. 
There has been a sizeable increase in the proportion of people under treatment for hypertension since the 1960's, according to the figures in Table 1. Two of the seven projects did not differentiate between the category "unaware of having hypertension" and the category "aware of having hypertension, but not under treatment for it." However, these two categories together accounted for an estimated $67 \%$ of the hypertensive population of Detroit in the late 1960 's but only $37 \%$ of the hypertensive people from the recent projects.

Nevertheless, the proportion found to be under adequate treatment (BP readings below $140 / 90 \mathrm{~mm} \mathrm{Hg}$ ) has not increased by any sizeable amount. Only $16 \%$ of the hypertensives screened in the seven projects were under adequate treatment at the time of screening, as compared with $9 \%$ in the earlier Detroit study. While the changes evident in Table 1 are clearly improvements, one may nevertheless conclude that "public education" has not resulted in adequate hypertension con-

TABLE 1

Awarengss and Treatment of People witil High Blood Pressure

\begin{tabular}{|c|c|c|c|c|c|c|}
\hline & $\begin{array}{l}\text { Unaware } \\
(\%)\end{array}$ & $\begin{array}{l}\text { Aware, no } \\
\text { treatment }\end{array}$ & $\begin{array}{l}\text { Inadequate } \\
\text { treatment }\end{array}$ & $\begin{array}{l}\text { Adequate } \\
\text { treatment }\end{array}$ & $\begin{array}{l}\text { Total } \\
(\%)\end{array}$ & $(\mathrm{N})$ \\
\hline \multicolumn{7}{|l|}{ Baseline data } \\
\hline U.S. population ${ }^{a}$ & 50 & 25 & 12.5 & 12.5 & 100 & - \\
\hline Detroit population ${ }^{b}$ & 51 & 16 & 24 & 9 & 100 & - \\
\hline \multicolumn{7}{|l|}{$\begin{array}{l}\text { Recent estimates in } \\
\text { the Detroit area }\end{array}$} \\
\hline \multicolumn{7}{|l|}{ Industrial settings ${ }^{c}$} \\
\hline (auto workers) & 28 & 6 & 40 & 26 & 100 & (159) \\
\hline $\begin{array}{l}\text { Municipal sanitation } \\
\text { workers }\end{array}$ & \multicolumn{5}{|c|}{ Municipal sanitation } & (151) \\
\hline \multicolumn{3}{|l|}{ U.S. postal service } & 29 & 16 & 100 & (116) \\
\hline $\begin{array}{l}\text { Manufacturing plant } \\
\text { employees }\end{array}$ & \multicolumn{5}{|c|}{ Manufacturing plant } & (149) \\
\hline \multicolumn{7}{|l|}{ Community settings ${ }^{d}$} \\
\hline \multicolumn{7}{|l|}{ Hospital visitors } \\
\hline $\begin{array}{l}\text { Drug store chain no. } 1 \\
\text { customers }\end{array}$ & \multicolumn{2}{|c|}{39} & 50 & 11 & 100 & $(1058)$ \\
\hline \multicolumn{7}{|l|}{ Drug store chain no. 2} \\
\hline Total & & 37 & 47 & 16 & 100 & (2231) \\
\hline
\end{tabular}

a Estimated by the National Heart and Lung Institute from 1960-62 surveys of American adults, 18 to 79 years of age.

'Estimated by The University of Michigan's Program for Urban Health Kesearch, from a 196869 survey of Detroit area residents, 25 to 60 years of age.

c Four Detroit-area projects undertaken by the authors in 1974-76, under contracts with the Michigan Association for Regional Medical Programs, DHEW.

a Three Detroit-area projects undertaken in $1974-76$, jointly sponsored by the hospital and drug store chains involved, and by the Hypertension Coordinating and Planning Council of Southeastern Michigan, of which the authors are members. 
trol as of this date. Even the groups showing the best treatment status show only one-fourth of their hypertensive members to be under adequate control.

A second strategy for controlling hypertension that has been widely attempted is that of community screening programs, which attempt to identify people with high blood pressure readings and refer them to the physician $(4,9,14,15)$. Some of these programs have succeeded in screening large numbers of people [for example, the CIBA CHEC Program (15)], and some have made special attempts to reach working people by screening inside industrial organizations (14). Some have manipulated variables such as ease of access to medical care and degree of knowledge about hypertension, in addition to screening (13), but few have made more than a perfunctory attempt to insure that people with high readings actually see a physician, and fewer still have included on-going provisions for dealing with subsequent treatment failure and dropout.

The classic study in Baldwin County, Georgia (18), demonstrated the efficacy of screening with follow'up. In Baldwin County, the adequacy of control in the hypertensive population rose to $80 \%$ during the program. But the study also demonstrated the futility of short-term follow-up. Two years after the follow-up was discontinued, the adequacy of control had dropped to $29 \%$.

It is apparent that screening, even with short-term follow-up, is not a satisfactory method of controlling high blood pressure; it does not work in the long run. Because of this, a variety of small-scale clinical projects have been developed focused on improving patient motivation and increasing compliance with therapy; for example, projects focused on the improvement of the patient-practitioner relationship (6) or projects based on behavior modification therapy.

In order for such approaches to be effective in lowering the rate of uncontrolled hypertension, however, they must be available to large numbers of people. This implies that the majority of private practitioners need to adapt their treatment methods based on these more intensive clinical models. Perhaps physicians should do this, but it is unrealistic to expect that they will, given heavy patient loads and traditional ways of practicing medicine. It may be that gradually over time more physicians and clinics will hire specially trained nurses or other paramedical assistants to work with hypertensive patients in this way. But for the time being, these intensive clinical approaches to hypertension control do not appear to be practical.

In summary, the strategies outlined above do not offer much promise for the wide-scale, long-term control of hypertension.

\section{PROCEDURES}

In light of these considerations, a model was developed for controlling hypertension that includes a broad screening component, in conjunction with follow-up and data-management components that do not require significant changes in the practice of the attending physicians, but that can be carried on by organizations external to the treatment units.

Figure 2 shows the components of the model system. Note that diagnosis and treatment are provided by physicians in the community, rather than being provided as part of the program. In this regard the model differs from Alderman's very successful programs among employee groups in the New York area $(1,2)$ 
which provide the option of treatment within the program. The provision of treatment was not necessary in the Detroit area where the model in Fig. 2 was tested, since there are sufficient numbers of private practitioners and most people prefer to be referred to their own physician. Furthermore, in Alderman's programs the employees' health benefits covered the costs of treatment, so that the provision of on-site treatment was not an additional cost to the organizations administering the health benefits, but rather an alternative cost.

The hypertension control model that was developed was therefore focused on providing those components of an effective system that are not available in the existing health care delivery system. These include (a) dissemination of information about hypertension to people in the target population, (b) screening of the target population for high blood pressure, (c) referral of those with high readings to a physician, (d) follow-up on a routine, on-going basis with the referred persons

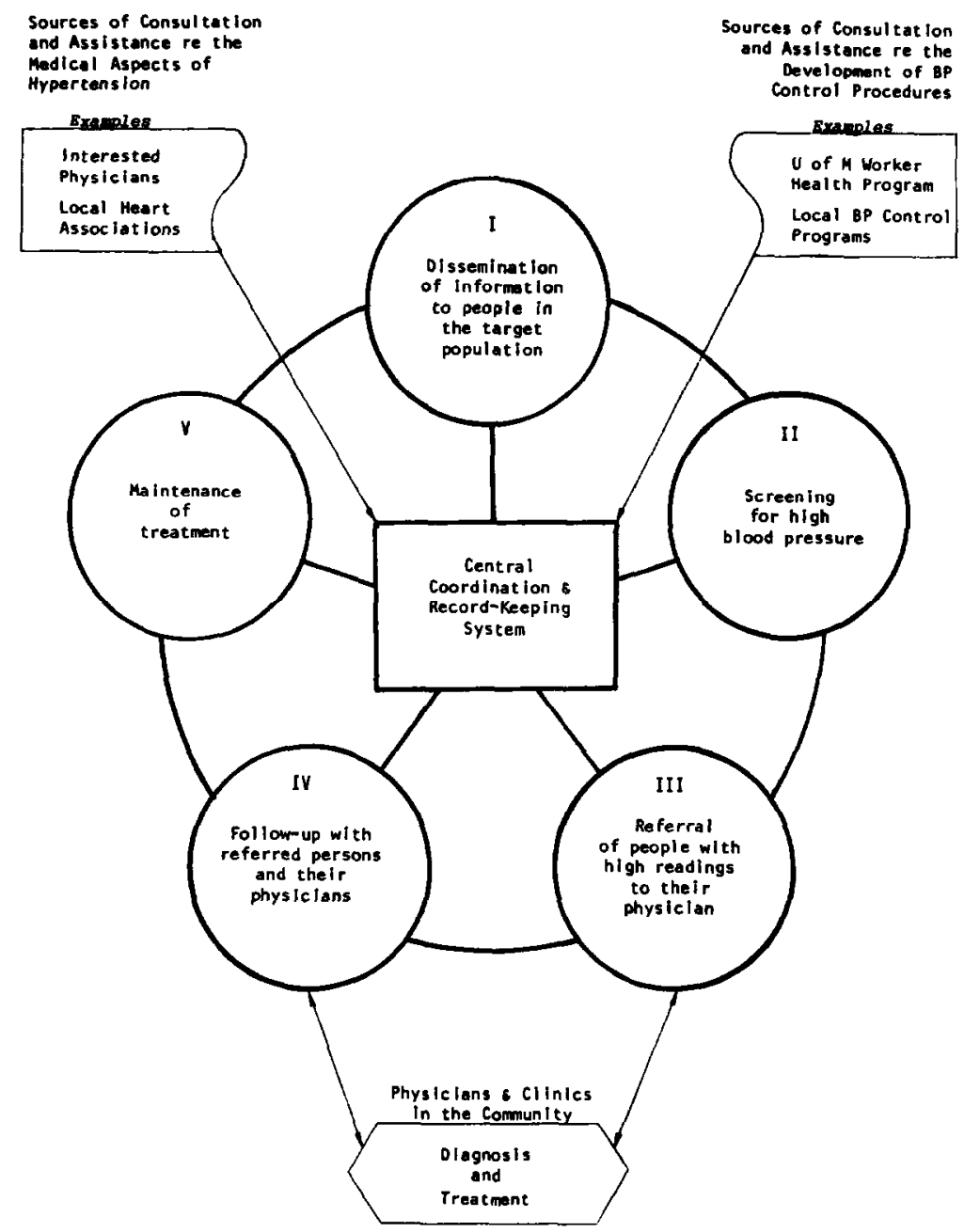

Fig. 2. Components of the model blood pressure control system. 
and with their physicians, (e) assistance for people having difficulty beginning and maintaining treatment, and (f) central coordination and record-keeping.

The first three components, dissemination of information, screening, and referral, are largely carried out as part of a single set of operations at the screening site(s). While a certain amount of advance publicity is helpful in notifying the target population of the time and place of screening and catching their interest so that they will come, a few minutes spent by the screener explaining to each person what his/her blood pressure is and what it means appear to have much more substantial impact as a means of education.

The screening and referral procedures utilized in this system are summarized in Table 2. [Complete documentation of these procedures has been published elsewhere (5).] The length of time taken for the initial screening depends upon the amount of information to be collected. Gathering a minimum of information, the system requires an average of 8 min per person screened (client), which includes the time to take three blood pressure readings, gather other pertinent information, explain the readings to the client, answer his/her questions, and carry out the necessary referral procedures for those with high readings. The range of time is about $4 \mathrm{~min}$, for people with normal readings and few questions, to $15 \mathrm{~min}$ or more, for people who wish to talk extensively with the screener.

The system does not require secondary screening of people whose initial readings are high (i.e., who have at least two out of three readings in the high range-a systolic of $160 \mathrm{~mm} \mathrm{Hg}$ or higher and/or a diastolic of 95 or higher). Evidence (to be shown below) indicates that an immediate referral to a physician can be made with a relatively small chance of referring a false positive, if screening is carried out in a calm and familiar environment.

Clients with readings in the borderline range are requested to return for a secondary screening, at which time three readings are again taken, and the person is referred to a physician if two of the three readings are $150 / 90$ or higher.

As noted earlier, most people in the Detroit area have a private physician of choice. However, each screening site is prepared with a list of physicians and clinics that have agreed to accept referrals, and persons desiring to see a physician from that list are offered a choice.

It should be noted that almost any screening system is adequate, if done by well-trained screeners who can take accurate readings and who can relate well to the clients and give them the necessary information. Referral guidelines can be adjusted to the situation, and the amount of information to be collected depends upon the use that the program wishes to make of it. The referral guidelines shown in Table 2 were developed in cooperation with area physicians to insure that they would be appropriate to the treatment provided by those physicians.

Similarly, while the guidelines in Table 2 call for immediate referral of people with high readings, rather than secondary screening, there is nothing wrong with a secondary screening if it can be done conveniently. However, if secondary screening requires a major effort to get people back to a screening site, then many people can be lost from the system who could have been referred upon initial screening. The procedures described here are the minimum necessary for an effective program. 


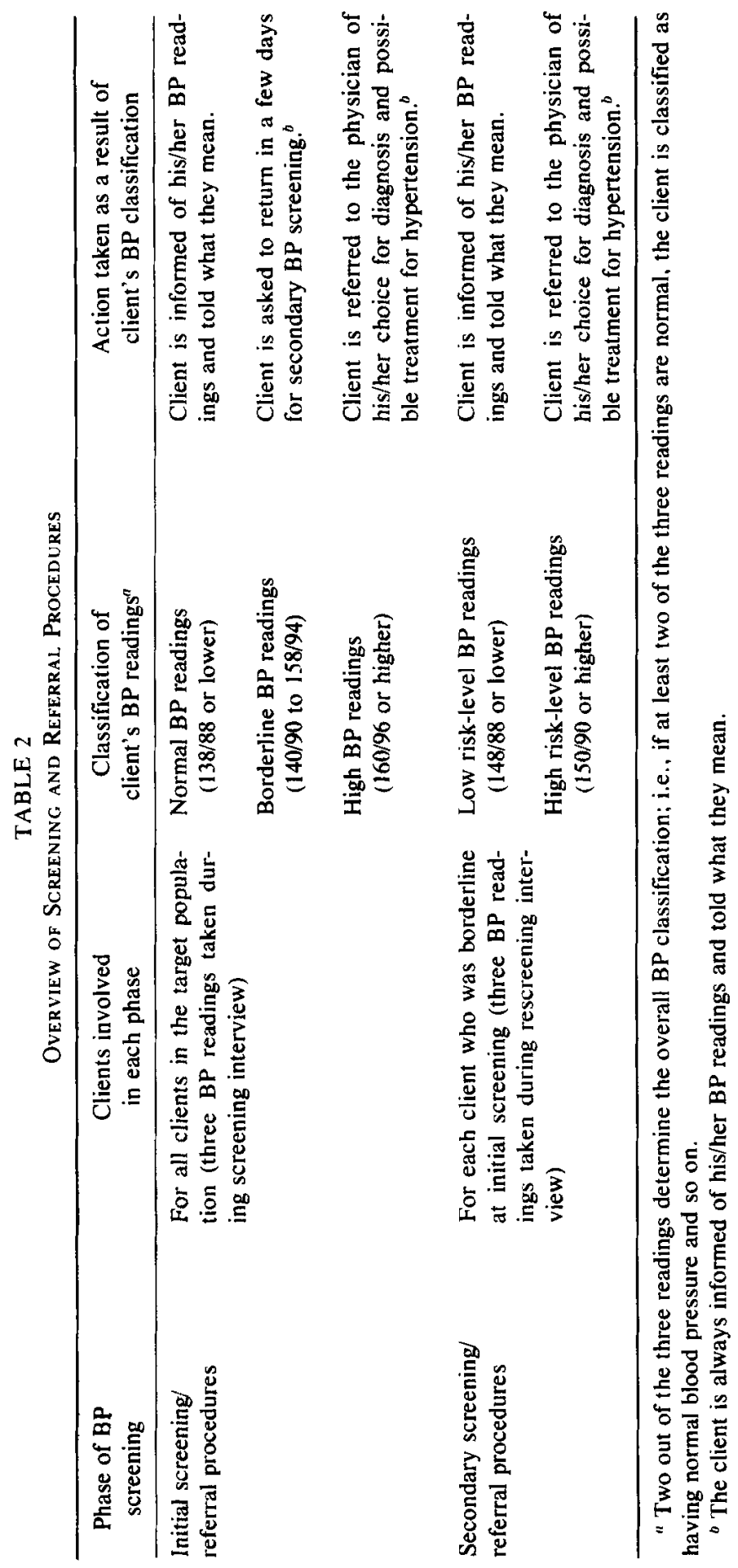


All people who are referred to physicians for elevated blood pressure (either at initial or secondary screening) are asked to sign a Medical Authorization, allowing the program to (a) release information concerning the person's blood pressure and health history to his/her physician and (b) gather information from the attending physician regarding the person's condition, including blood pressure readings, diagnosis, and prescribed treatment.

All people referred to a physician become clients in the follow-up caseload. The follow-up and treatment maintenance procedures can rely primarily on mail and telephone contacts; however, an in-house program (e.g., a program for employees in a work setting) can utilize the same procedures, employing more frequent face-to-face contacts with its clients.

The first objective of follow-up, aside from the simple gathering of information about the client's status, is to insure that the client does see a physician about his/her blood pressure. The second objective is to insure that, if antihypertensive treatment is prescribed, it is begun and maintained and that return visits to the physician are made as appropriate. Follow-up is carried out with both the client and the physician to insure accurate information.

Table 3 shows the overall procedures used for follow-up, along with the cumulative response rates for both clients and physicians. [Again, these procedures have been thoroughly documented elsewhere (5).] The initial wave of follow-up requires a letter and follow-up form mailed to the client about 2 weeks after referral. The letter reiterates the information given to the client by the screener, and serves as a reminder to make an appointment with the physician in case the client has forgotten. Approximately 2 weeks after that, a cover letter, follow-up form, and Medical Authorization signed by the client are mailed to the physician.

In the second step of follow-up, telephone calls (or face-to-face visits with clients where feasible) are instituted for all clients and physicians who did not return the follow-up form, as well as for clients who have not seen a physician or who need to be contacted for some other reason. The phone calls and visits have the purpose not only of gathering information but also of inducing the client to follow the prescribed therapy and to see the physician as required.

Some of the physicians contacted by phone will indicate that they did not receive the initial forms and will request that duplicate forms be sent in the mail. Step 3 of the follow-up procedures thus involves the mailing of duplicate follow-up forms to physicians making such requests.

Step 4 in Table 3, "Subsequent follow-up contacts," indicates the second wave of follow-up contacts carried out with clients and physicians about 6 months after successful referral. These types of contacts (either by mail or phone) are carried out approximately every 6 months for those clients who were diagnosed as having hypertension and placed on treatment. More frequent contacts are made with people who do not show satisfactory progress toward successful treatment.

Thus, in terms of being able to follow up with clients and physicians, Table 3 demonstrates that most of these people can be successfully contacted using these procedures and that they will provide the required information through the mails or over the telephone.

The central coordination and record-keeping component of the system provides a means for coding the results of each interaction with the client and each interac- 


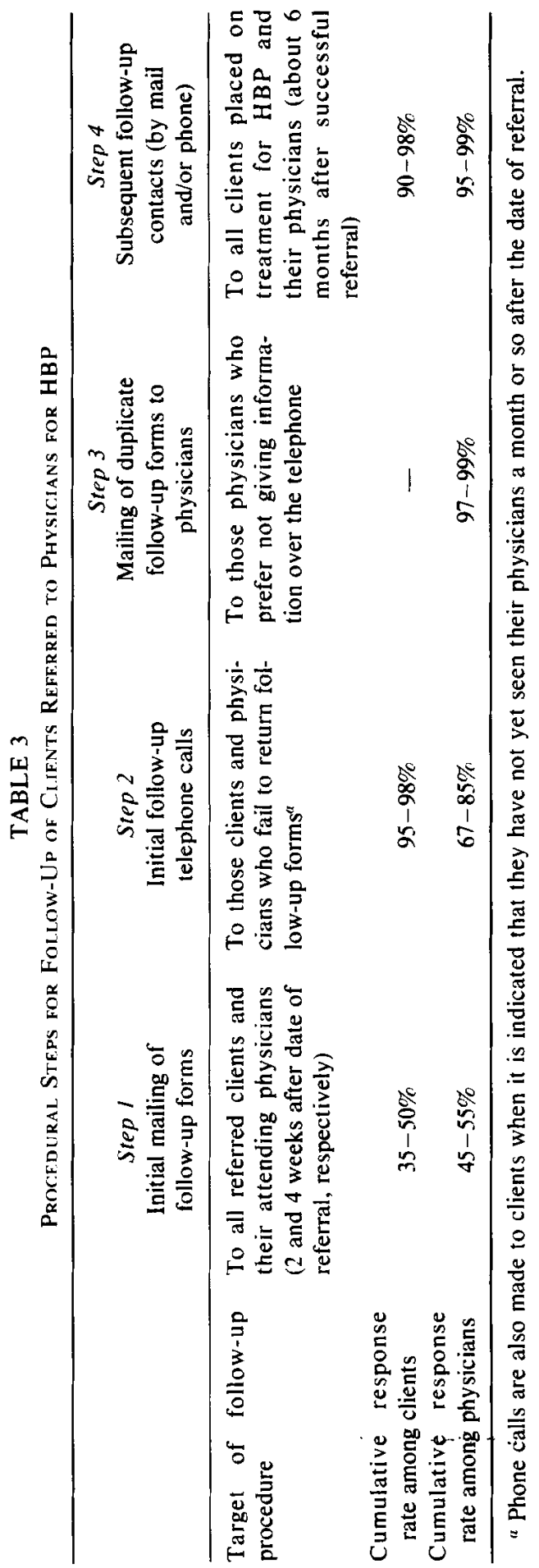


tion with the physician, so that at any point in time the program can identify the blood pressure status of each client, as reported by the client and as reported by the physician (5). This system is designed to be useful both for service delivery purposes (e.g., "tagging" those clients who need further assistance in beginning or maintaining treatment) and for program evaluation purposes (e.g., providing summary data on the current status of all clients in the caseload). The system is adaptable to computerization for quick storage and retrieval but can be managed as a paper system as well.

The model described above was initially developed and tested beginning in 1974 in projects that focused on the work force or membership of three industrial organizations: A local labor union associated with an auto manufacturing plant, a municipal sanitation department, and three postal stations of the U.S. post office. The overall objectives of the three projects were (a) to test the feasibility of the model and (b) to test its cost-effectiveness, that is, to see whether or not the model would result in the effective control of hypertension within the target group without costing more than the amount to be saved by the organization due to reduction in cardiovascular events.

The model was subsequently implemented and tested in three community sites that screened people passing through their facilities: A large community hospital and two drug store chains. The remainder of this paper presents data on the results of those six projects, the cost of the procedures that were used, and a discussion of the model's potential for effective hypertension control.

\section{RESULTS}

Table 4 shows the screening results for the six projects. In the industrial sites. success of screening can be evaluated with reference to the number of employees in the target organization. Among the auto workers, only $20 \%$ of the target group was screened because screening was carried out away from the work site (at the local union hall), requiring that a special effort be made to appear for screening. At the other two industrial sites, screening was carried out right at the work site, and $80 \%$ of both groups of workers were screened.

The numbers screened in the community sites were a function of the duration of the screening; all three sites were dealing with an essentially unbounded population, so that coverage of the target population is very difficult to evaluate. (However, if demographic information is collected from the clients and the program has some estimate of the demographic characteristics of the target population, then evaluation can be carried out regarding the segments of the population being reached.)

The percentage found to have high blood pressure (peoplc with observed high readings, plus those who had been previously diagnosed as hypertensive and were under treatment) varied across the six groups, primarily as a function of differential age. Those client groups with a relatively high prevalence of high blood pressure (community hospital clients and sanitation workers) were the oldest groups screened, whereas those groups with a relatively low prevalence of high blood pressure (auto workers and postal workers) were the youngest groups on the average. 
TABLE 4

Results of Screening for Six Blood Pressure Control. Projects

\begin{tabular}{lccccccc}
\hline & \multicolumn{3}{c}{ Industrial sites } & & \multicolumn{3}{c}{ Community sites } \\
\cline { 2 - 3 } & $\begin{array}{c}\text { Auto } \\
\text { workers }\end{array}$ & $\begin{array}{c}\text { Sanitation } \\
\text { workers }\end{array}$ & $\begin{array}{c}\text { Postal } \\
\text { workers }\end{array}$ & $\begin{array}{c}\text { Drug store } \\
\text { chain no. 1 }\end{array}$ & $\begin{array}{c}\text { Community } \\
\text { hospital }\end{array}$ & $\begin{array}{c}\text { Drug store } \\
\text { chain no. 2 }\end{array}$ \\
\hline $\begin{array}{l}\text { Number of people screened } \\
\begin{array}{l}\text { Percentage of target } \\
\text { population }\end{array}\end{array}$ & 933 & 463 & 580 & 3772 & 808 & 1115 \\
$\begin{array}{l}\text { Percentage with high blood } \\
\text { pressure }\end{array}$ & 20 & 80 & 80 & $?$ & $?$ & $?$ \\
$\begin{array}{l}\text { Percentage referred to } \\
\text { physicians for } \\
\text { uncontrolled } \text { high } \\
\text { blood pressure }\end{array}$ & 20 & 36 & 23 & 29 & 41 & 28 \\
\hline
\end{tabular}

${ }^{n}$ Includes people with observed high blood pressure readings plus people with normal or borderline readings who had been previously diagnosed as hypertensive and were under treatment.

${ }^{b}$ Includes only those people with observed high blood pressure readings.

The percentage of those screened who had controlled hypertension can be found by subtracting the percentage with uncontrolled high blood pressure (the bottom row of Table 4) from the percentage with high blood pressure. This figure ranged from 5-9\% among clients at the industrial sites and drug store chain no. 1, to $15-17 \%$ among clients at drug store chain no. 2 and the community hospital. The better control exhibited among clients at the latter two sites is at least partially attributable to the large numbers of retired people in those two populations, along with the fact that people screened at the community hospital were by definition found in a health care setting.

All of the people with uncontrolled high blood pressure (those with observed high readings) were referred to a physician for further evaluation. Follow-up was then carried out with these clients and their attending physicians to insurc successful referral, and maintenance of treatment for those clients placed on antihypertensive therapy.

Table 5 provides data on the effectiveness of screening and referral for each of the six projects as of June 1976. Since follow-up is on-going, the data change whenever new information is gathered. Section $A$ of this table shows the average duration of follow-up for the data reported here. The average duration of the follow-up period ranged from 19 months for the auto workers (i.e., the auto workers were screened on the avcrage of 19 months prior to June 1976), to 7 months for the clients at drug store chain no. 2.

Section B of Table 5 shows the referral status of all clients in the follow-up caseload. In five of the six projects, fewer than $10 \%$ of the referred clients were unsuccessfully referred, i.e., had failed to see a physician about their blood pressure as of June 1976. In the most recent project (drug store chain no. 2), 16\% were unsuccessful referrals. It appears that a $90 \%$ successful referral rate is a reasonable goal and that reaching this goal requires more than 7 months of follow-up. 


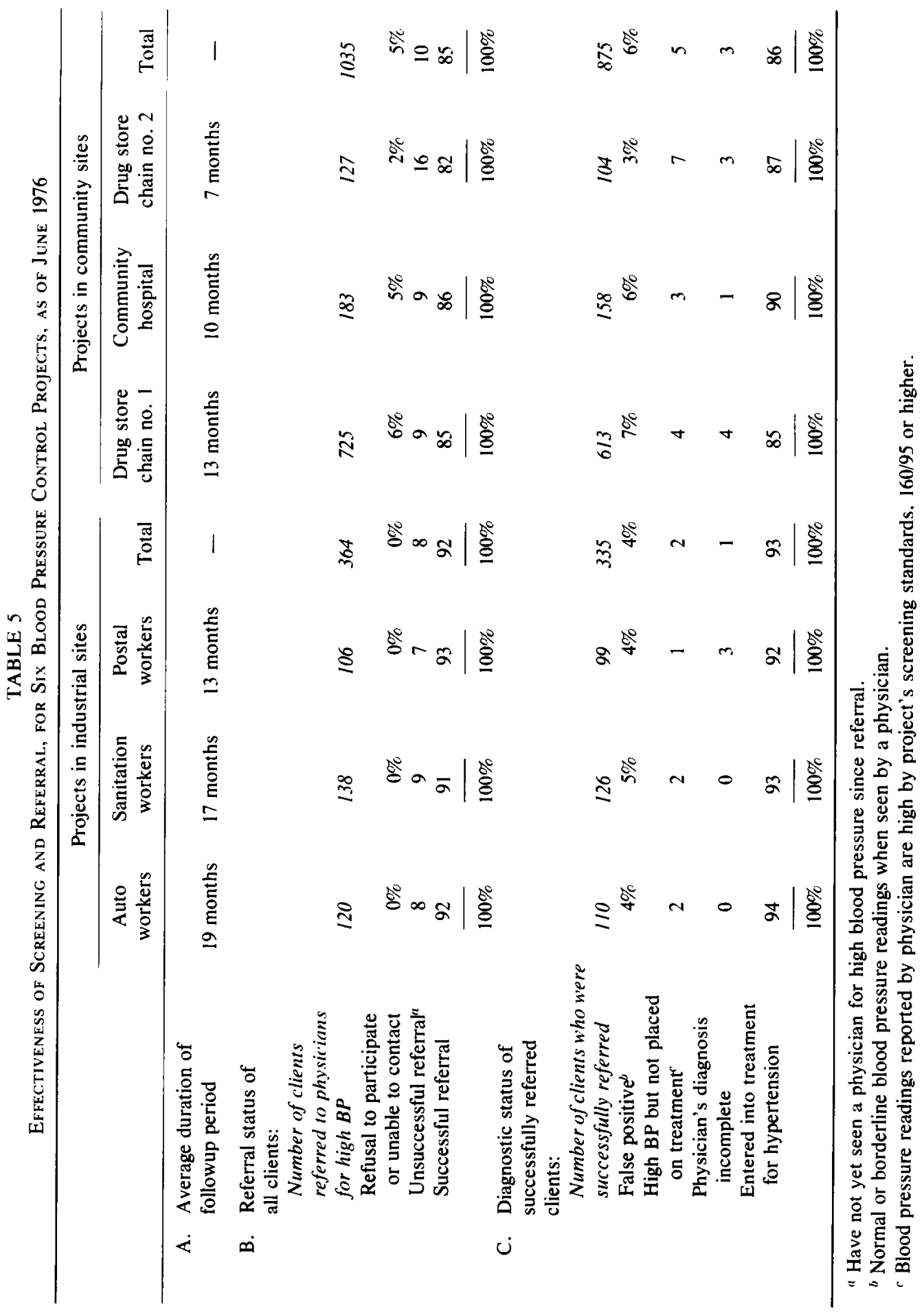


For all six projects, the initial wave of follow-up showed at least $25 \%$ unsuccessful referrals. (For some projects, this figure was as high as $45 \%$.) The followup staff were trained to work with those clients, using as many follow-up contacts as necessary, until they did see a physician. Subsequent waves of follow-up showed successive reductions in the percentage of unsuccessful referrals, to the present levels, and follow-up is continuing with those who have still not seen a physician.

In the three community sites, $5 \%$ of the referred clients either refused to participate in the project or could not be contacted. (For these clients, follow-up with their physicians was equally impossible because their attending physicians, if they had any, could not be identified.) There were no such cases among referred clients in the industrial sites. Projects in industrial sites have captive populations (employees in the target organization), whereas screening sites in the community attract some people who are difficult or impossible to contact later on.

Section $C$ of Table 5 examines the diagnostic status of the clients who were successfully referred. The false positive rate was $4 \%$ for projects in industrial sites and $6 \%$ for projects in community sites. That is, only $4-6 \%$ of the people seen by a physician were found by the physician to have blood pressure readings below $160 / 95 \mathrm{~mm} \mathrm{Hg}$, and were not diagnosed as hypertensive. (As noted in the screening guidelines, the program did refer people with borderline readings on subsequent screening dates, and many physicians did diagnose hypertension for people with sustained borderline readings.) It was felt that a false positive rate of less than $10 \%$ was well within tolerance levels and that the low rates experienced by the six projects support the screening and referral procedures that were used.

The next category, "High blood pressure, but not placed on treatment," is composed of people who were not diagnosed as hypertensive by the physician but whose blood pressure readings were reported by the physician to be 160/95 or higher. These figures allow an evaluation of the degree to which physicians in the community agree with the program's referral guidelines. Only $2 \%$ of the clients in the industrial projects and $5 \%$ in the community projects went to physicians who did not place them on treatment despite the high readings in the physician's office. These low rates demonstrate a high degree of agreement among area physicians that sustained blood pressure of $160 / 95$ or higher indicates hypertension.

For 1 and $3 \%$ of the clients in the industrial and community projects, respectively, the physician's diagnosis was incomplete, indicating how recently those clients had finally been induced to see a physician about their condition. Further follow-up investigation is required to ascertain the physician's decision on treatment.

The final piece of information evaluating the effectiveness of screening and referral is the proportion of successful referrals who were diagnosed as hypertensive and placed under treatment. In the industrial sites, $93 \%$ of the successfully referred clients were being treated for hypertension as of June 1976, and in the community sites, $86 \%$ had entered into treatment for hypertension. Most of the clients in these two groups represent new hypertensive patients who had entered treatment for the first time in their lives; the remainder are those who had reentered treatment after having dropped out. 
Table 6 provides data on the effectiveness of follow-up and treatment for the six projects by examining the treatment status of those clients placed on antihypertensive therapy. The first category, "Treatment just begun, or dropouts back into treatment," includes people who have not been under treatment long enough to show reductions in blood pressure. These figures represent those who required a considerable amount of inducement to see a physician and begin treatment. The greater numbers in two of the three community sites (15\% for the community hospital and $18 \%$ for drug store chain no. 2) are largely a function of the shorter duration of those projects. (In general, initiation of treatment results in fairly quick reductions in blood pressure. However, the projects did not attempt to actually monitor the client's blood pressure, but rather relied on information based on the client's visits to the physician. An in-house program that opts for more face-toface follow-up visits will have faster feedback, by measuring the client's blood pressure during these visits.)

Unsuccessful treatment due to noncompliant behavior on the part of the client was a very small item in all six projects. Only $3 \%$ of the clients under treatment in the industrial projects, and $4 \%$ of those in the community projects, fell into this category. These include those clients who were reported to be noncompliant in honoring return appointments with the physician and those who were not complying with their treatment regimens. The low noncompliance rates reported here lend support to one of the hypotheses developed during the course of these projects-that noncompliance is a relatively minor problem when effective follow-up procedures are employed.

The third category in Table 6, "Unsuccessful treatment, don't know why," includes some $2-3 \%$ of the clients under treatment. These are people for whom the currently prescribed treatment is inappropriate or insufficient, along with people who are not complying with the treatment but for whom there is no evidence to that effect. Our experience indicates that in many of these types of cases there is a need for changing or tailoring medication to the needs of the individual patient.

The fourth category includes people whose treatment regimen had been recently changed by their physician because of inadequate response to previous therapy. Of the clients under treatment. another 2-3\% were in this category.

Finally, the largest category, "Successful treatment, blood pressure has dropped," includes people who have achieved normal blood pressure (below 140/90) and people whose blood pressure has dropped since screening and is below 160/ 95. In the industrial sites, $84 \%$ of all clients under treatment were in this category as of June 1976, and in the community sites, $79 \%$ were under successful treatment. It appears that $80 \%$ is a reasonable short-range goal for this measure. However, none of the projects has continued long enough to provide any information about long-term maintenance of treatment.

\section{DISCUSSION}

Table 7 provides a summary of the overall effectiveness of the six blood pressure control projects. Although the same basic procedures were used in all six projects, those in the industrial settings show somewhat better results than those 


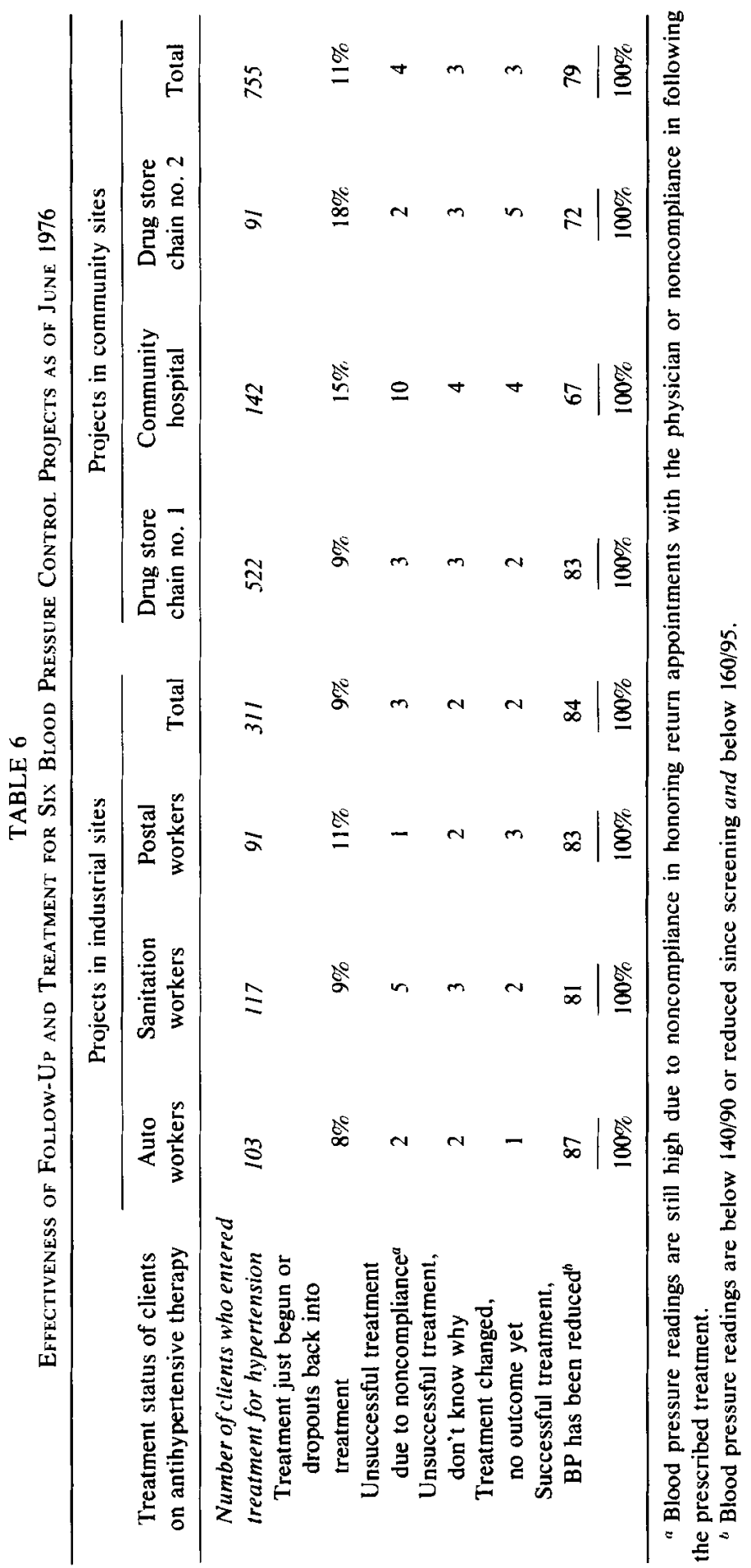


FOOTE AND ERFURT

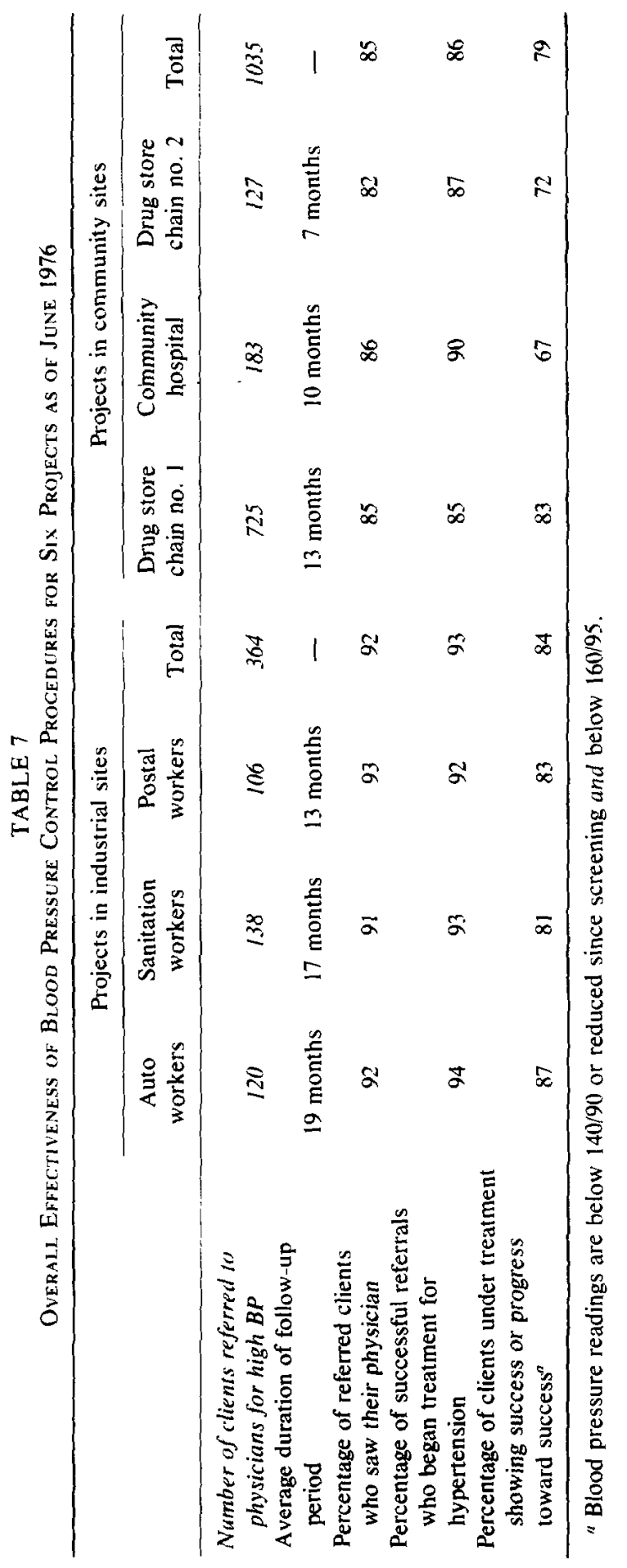


in the community settings. For the projects in industrial sites, $92 \%$ of the clients with elevated blood pressure readings had seen a physician (as of June 1976), 93\% of those had been diagnosed as hypertensive and placed on therapy, and $84 \%$ of those on therapy showed blood pressure reductions since screening (with readings below 160/95) or had attained blood pressure control (with readings below 140/90).

The summary figures for projects in community settings were somewhat lower but still substantially higher than for programs that do not include routine, regular follow-up procedures. In the community sites, $85 \%$ of the referred clients had actually seen a physician (as of June 1976), 86\% of those were diagnosed as hypertensive and placed on therapy, and $79 \%$ of those showed satisfactory progress (i.e., blood pressure readings below 140/90 or reduced since screening and below 160/95).

The higher degree of success attained by the projects in industrial settings reflects, in part, the greater ease of access to the clients in these settings. The auto workers were screened in their union hall and the sanitation and postal workers at their work site. The drug store chains and the hospital, however, simply screened people passing through the site (the drug stores and the hospital lobby), making it more difficult to locate and contact these people for follow-up. In addition, the projects in industrial settings began somewhat before those in community settings, so that the follow-up period was somewhat longer.

A number of comments may be made about this model for blood pressure control and the results of the six projects that used the model. First, it was pointed out that diagnosis and treatment are not provided as part of the program; physicians in the community are relied upon for these services. Many people have worried that hypertension control programs of this type would result in an unreasonable demand on the community's physicians. However, existing medical services in places like the Detroit area have the capacity to absorb a great many referrals, mainly because large numbers of people do have their own physicians. While these people may not have seen the physician for some time, they are nevertheless in the physician's caseload and do not really represent new patients. In addition, case-finding progresses in a gradual way, so that only a few new hypertensive patients have to be absorbed at a time. The availability of physician care is therefore not an immediate problem, except for indigent populations, and was not a major focus of these projects.

In some geographical areas, of course, there is not an adequate number of physicians, and additional treatment facilities may have to be developed before a hypertension control program is begun. However, in southeastern Michigan where this model was tested, there is a sufficient number of private practitioners, and these have been overwhelmingly cooperative with the various projects.

The data reported earlier support the validity of the screening procedures used, in that very few people referred to a physician (only $5 \%$ across all six projects) were found to be false positive. It should be noted that people were classified as false positive on the basis of the physician's report, not solely on the client's report. During the first wave of follow-up there are some people who will tell the program that they did see a physician and were told that their blood pressure was fine; however, in many cases the physicians do not confirm this, but indicate 
instead that they have not in fact seen the client. These people are not classified as false positive but rather as unsuccessful referrals (until they do in fact see a physician).

It was felt that a false positive rate of $5 \%$ was well within tolerance levels, and this rate supports the screening procedures used. Had the false positive rate been above $10 \%$, the referral guidelines would have been adjusted to require a secondary screening for all people before making a referral.

It may be noted that the false positive rate, as well as the rate for the category "High BP, but not placed on treatment," tends to shrink over time. The rates found in the first wave of follow-up were somewhat higher than those in subsequent waves because a number of people who had initially been classified by their physicians as false positive were later diagnosed as hypertensive and placed on treatment. These are people with labile blood pressure, high at the screening site but normal or borderline in the physician's office. Referring these people may thus be justified in alerting their physicians to the situation and allowing a closer monitoring of their blood pressure in subsequent office visits.

Problems of patient noncompliance were successfully handled through the screening, referral, and follow-up procedures; only about $4 \%$ of the clients under treatment were reported as having these problems. Throughout the follow-up activities, it was found that most of the problems experienced by clients that could or did lead to discontinuation from treatment, or noncompliance with treatment, were problems of misinformation or insufficient information. These people did not have to be "motivated to comply;" rather, they had to be given adequate information about their condition and about the prescribed therapy.

The provision of adequate information usually required considerable redundancy. The fact that people do not comprehend or remember everything their doctor tells them is well known; people do not remember everything that anyone else tells them, either. But patients tend to be a little on edge in the doctor's office, anxious to get back to their other affairs, sometimes concerned about taking up too much of the doctor's time, and often unable to frame their questions in time to ask them. It is not surprising, then, to find that many people discontinue medication because they do not know that they should refill the prescription, or because the doctor tells them on a subsequent visit that they are doing fine and they think they are cured, or because they believe the drugs cause impotence, or because they have not understood the seriousness of high blood pressure.

The follow-up interactions with a specially trained nurse or paraprofessional worker, either by telephone or in person, allow these issues to be discussed in a less urgent atmosphere than that which sometimes exists in the clinic or doctor's office, and they provide the opportunity to clarify, interpret, and reinforce any instructions given to the client by his or her physician. And, of course, the follow-up contacts allow the identification of people who have discontinued their treatment, for whatever reason, so that the problems leading to discontinuation can be addressed.

We feel that the overall high success rates experienced by the six projects discussed above can be attributed to (a) effective screening techniques, which emphasize consumer education about high blood pressure; (b) adequate referral 
guidelines, which are generally acceptable to medical practitioners in the area; and most importantly, (c) supportive long-range follow-up procedures with both clients and their attending physicians.

The act of follow-up itself has a major effect on successful referral and maintenance of treatment. We call this a "program effect," and it works on physicians as well as clients. Regarding physicians, experience suggests that people referred by a screening and follow-up program are more likely to be diagnosed as hypertensive and placed on therapy than people with comparable blood pressure who come to the physician for other reasons. This may be partly because the client is coming specifically about his or her blood pressure, and thus the physician pays special attention to it. And it may be partly because the physician receives a letter from the program which outlines the referral criteria and provides some impetus for the physician to treat people with sustained blood pressure readings above those criteria.

From the client's point of view, the act of follow-up serves to remind the client about his or her blood pressure condition; this is important in that an asymptomatic disease like hypertension is easy to forget about. Beyond the mere reminding, follow-up reinforces that the disease is serious enough for someone to spend time and resources on a blood pressure control program. Finally, the fact that someone is concerned enough about them is, for some people, instrumental in inducing them to see a physician and to begin and maintain treatment.

The figures shown in Tables 5 and 6 represent information that few blood pressure control programs can produce, either because they do not continue follow-up long enough to gather this type of information or because they have no data management system that allows them to compile and update the information. The development of a data management system that facilitates the storage and retrieval of the kind of information reported above is essential to an effective program. Moreover, the system must be usefurfor service delivery purposes (c.g., identifying those clients for whom a new follow-up action is appropriate, or summarizing the blood pressure history of each client being followed), as well as for program evaluation purposes (e.g., summarizing the current status of the entire client caseload, or computing the number and type of contacts with each client and physician).

The beauty of such a system is that if one cannot produce data of the type shown in the above tables, one has not provided the services required for an effective program. Or alternatively, if the program does perform the appropriate follow-up activities, it can easily produce the types of evaluative data shown in this report. Evaluation is built into the service delivery system (5).

\section{COST OF THE SYSTEM}

The search for effective methods of hypertension control must take account of costs as well as effectiveness. A method is useless if it does not work, but it is also useless if no one will pay for it. The question of who will pay for hypertension control is therefore closely tied to the question of who pays the costs of uncontrolled hypertension.

In societal terms, the Veterans Administration studies of the effectiveness of 
controlling high blood pressure as a prevention for cardiovascular events $(16,17)$ would support the cost-effectiveness of blood pressure control without question. However, we must consider more directly the cost of a program to the organization paying for it, as compared with any savings that would accrue to that organization.

Health expenditures in the United States have risen by a factor of nearly 10 in the past 25 years, from $\$ 12$ billion in 1950 to $\$ 118$ billion in 1975. A large proportion of these expenditures is paid in the form of insurance premiums, and a large proportion of these premiums is paid by employers as part of a fringe benefit package. In addition, there are other costs incurred by employers as a result of employee illness.

A major manufacturing company recently made a study of its health-related expenditures and found that costs due to cardiovascular illnesses accounted for an estimated $29 \%$ of all its health costs and amounted to over $\$ 300$ per employee, per year. Table 8 shows the distribution of those costs; it is notable that the largest cost-incurring factor was disability/early retirement, a cost not normally thought of as a health expenditure. Yet even if no early retirement and related disability costs were paid as a result of disabling cardiovascular events, the company would still be paying out over $\$ 150$ per employee, per year, due to cardiovascular diseases.

If we estimate conservatively that the control of high blood pressure can cut the incidence of cardiovascular events, and consequently their cost, by $20 \%$, then the cost of an effective blood pressure control program need only be kept under $\$ 60$ per employee, per year, to break even (eventually) for employers paying these types of benefits. Table 9 shows the cost figures for the first year of operation of a program utilizing the procedures described above. These estimates are based on the costs of operating the six projects reported above; the costs did not vary singificantly from one project to another. While screening costs will not vary

TABLE 8

Costs to a Company Due to Cardiovascular Disease:

Estimates made by a Large Manufacturing Firm ${ }^{a}$

Cardiovascular costs as a percentage of all medical costs:

Annual costs of cardiovascular diseases per employee:

Distribution of costs due to cardiovascular disease (\%):

Physician costs (Blue Shield)

Hospital costs (Blue Cross)

over $\$ 300$

Major medical

1.8

Medications

3.1

Life and disability payments

35.3

Sick pay

.9

Temporary replacement costs

Permanent replacement costs

Disability/early retirement

${ }^{a}$ Data presented by permission. 
TABLE 9

Cost of Blood Pressure Control Procedures Per 5000 People, Per Year

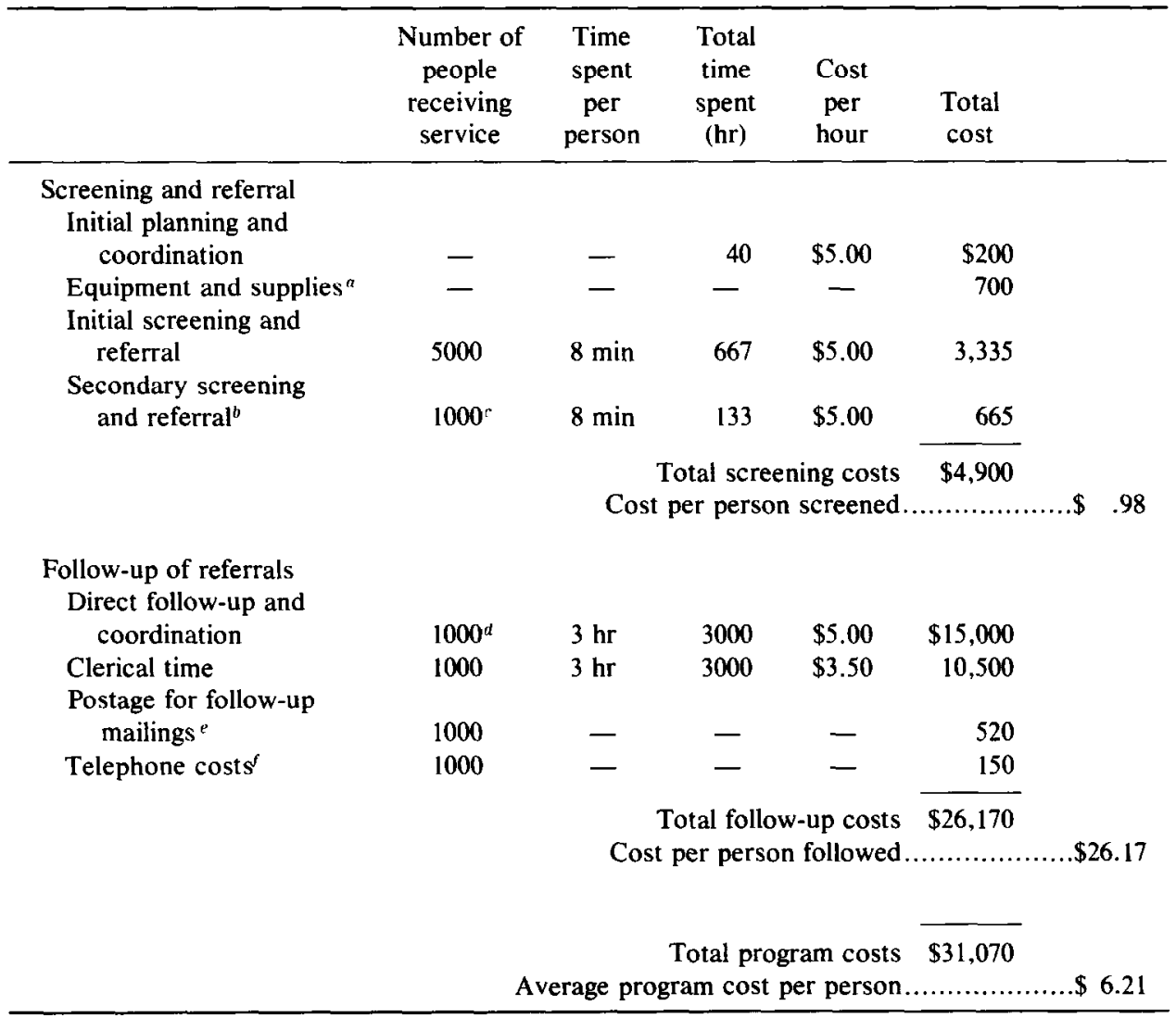

a Includes five sphygmomanometers and all forms and materials required for screening, referral, and follow-up procedures.

${ }^{b}$ Second screen for those people who had initial borderline BP readings.

c Assumes that $20 \%$ of the people will require secondary screening.

${ }^{a}$ Assumes that $20 \%$ of the people will be referred to physicians for diagnosis and possible treatment for hypertension.

- Average of four letters mailed per person being followed, ca. $13 \not$ per letter.

${ }^{s}$ Average of three phone calls per person being followed, ca. $5 \varnothing$ per phone call.

substantially from year to year (except for wage inflation) if the same number of people is screened, the follow-up costs will be reduced in subsequent years for a given group of clients. That is, the first year of follow-up will take more time than subsequent years of follow-up with the same client group.

The cost estimates in Table 9 are based on the assumptions that $20 \%$ of the group screened will require secondary screening (i.e., will have borderline readings on the initial screening) and that $20 \%$ of all people participating in the program will be found to have uncontrolled high blood pressure. Since most of the total program cost (about five-sixths) is for follow-up rather than screening, the total 
cost will be less if the proportion having uncontrolled high blood pressure is less than $20 \%$.

Screening costs are based on an estimate of $8 \mathrm{~min}$ per person screened at a pay rate of $\$ 5.00$ per hr for screeners. Including initial planning, coordination, equipment, and supplies, the cost of screening is less than a dollar per person screened.

If screeners must travel extensively, costs may have to be added, and if considerable slack time is expected, screening costs will go up accordingly. The estimated wage rate of $\$ 5.00$ per hour has been set in accordance with the cost of such services in the Detroit area and may be adjusted to fit local circumstances. In any case, the costs of screening can be easily estimated for a given program based on its own requirements.

Follow-up is the more expensive component. For the first year of activity, it is estimated that each client referred will require a maximum of $3 \mathrm{hr}$ of clerical time and $3 \mathrm{hr}$ of professional or paraprofessional time. These maximum estimates allow for slack time and training time, as well as time for overall coordination. Actual time per client averaged less than $2 \mathrm{hr}$ of clerical time and $2 \mathrm{hr}$ of professional time for the first year of the demonstration projects.

Overhead costs have not been included in these estimates, since, in general, overhead costs do not increase substantially when such a program is instituted in an existing organization. However, any organization can compute its own estimates regarding such costs. The important portions of the cost estimates depicted in Table 9 are the personnel time estimates.

In addition, costs for lost work time are not given for projects in industrial sites because this was not a factor in any of the three industrial projects. Even though in two of these projects the screening activities took place at the work site, these activities were carried out on the employees' time (during work breaks, lunch hour, etc.), not on company time. Furthermore, all of the follow-up activities were carried out with clients during those hours of the day when they were not at the work site.

During subsequent years of follow-up, clients will require much less time; on the average, it is expected that subsequent years of follow-up with a given client group will require no more than half of the time required in the first year.

Finally, while the screening and referral activities in the industrial sites took advantage of the fact of a "captive" population, by screening at or near the work site, the follow-up procedures did not take advantage of this fact. Follow-up was carried out through the mails and by telephone, from the program's central offices rather than from the work site. This resulted in much more time spent in trying to reach workers than should be the case for a program administered at the work site; that is, it often was necessary to make numerous phone calls before reaching a client, but making contact at the work place should generally take much less time. Consequently, the cost estimates (i.e., time estimates) for follow-up that are shown in Table 9 are higher than need be for a program that is located on-site and has easy access to the target population.

In summary, for a number of reasons the cost estimates shown in Table 9 are on the high side. Nevertheless, the overall per-person cost of the program is estimated at only $\$ 6.21$ per year. Referring back to Table 8 , it can be seen that the cost 
to that particular company of cardiovascular illness was over $\$ 300$ per person, per year. The control of high blood pressure within that company need save only $\$ 10$ per person, per year (i.e., reduce the costs of cardiovascular illness by about $3 \%$ ) to have more than paid for itself. Based on the outcome of the Veterans Administration studies, it would appear that controlling high blood pressure should reduce cardiovascular costs by much more than $3 \%$, thus resulting in considerable cost savings over time.

It should be pointed out that the program costs shown in Table 9 do not include any estimates for treatment of hypertension (physician fees, laboratory tests, medications). This is because these are not program costs; most of these costs are paid by the patients themselves. Few people in the Detroit area are covered by health insurance plans that pay any significant proportion of these treatment costs. However, a company that does pay these costs as fringe benefits (either directly or through insurance premiums) should be able to produce estimates of how those costs will increase, based on past expenditures. Such estimates cannot be produced here because treatment costs in the Detroit area vary widely depending on the source of treatment chosen, and clients were not asked to reveal how much they pay for treatment. In any case, treatment is not a part of the program described here and should not be included as a program cost unless it is provided or paid for by the organization that supports the program.

\section{CONCLUSIONS}

The data presented in this paper are for projects that have been in existence a relatively short period of time. Blood pressure control is a long-term process, and a major problem of blood pressure control is treatment dropout over time. Furthermore, the desired outcomes of blood pressure control require long-term measures: Reduction in cardiovascular events, and prolongation of life. One cannot therefore draw any definitive conclusions about the efficacy of the blood pressure control model described.

The data do suggest, however, that the model shows promise on several dimensions:

(1) It shows significant improvement in the adequacy of blood pressure control within the screened population without requiring alteration of medical practice by the attending physicians. Note that the absence of specified control groups does not invalidate these data. Frequent blood pressure screening activities serve to indicate that changes in the adequacy of treatment for hypertension in the population of southeastern Michigan cannot account for our findings.

(2) If routine screening and follow-up procedures are continued as outlined, it is reasonable to assume that the dropout problem will be handled and that high blood pressure will continue to be controlled within the target population, and subsequent reductions in cardiovascular diseases will become evident.

(3) For the industrial organizations, the available cost figures suggest that implementation of such a system should save many companies money in the long run. How long it will take is not yet clear.

(4) Most adults of working age have health insurance coverage that is paid, at least in part, by their employer (or their spouse's employer). If, as a goal, all 
employers that would benefit financially by controlling hypertension within their work force were to establish a program that did so, a major impact on the population as a whole would be evident.

(5) Programs in community settings are not as cost-effective as those in industrial settings; they are more costly because of less access to their target group, and the cost savings over time will not necessarily accrue to the organization paying for the program. But they nevertheless can successfully control blood pressure within the group they screen, at least in the short run, as evidenced by the data shown above.

(6) There are some institutions in the community that might benefit financially by supporting hypertension control programs in addition to employers, e.g., pharmceutical houses and drug stores. There are other institutions, e.g., public health departments, that may be mandated to improve health in the community and reduce health care costs, even though the cost savings would not necessarily accrue directly to those institutions. (However, a considerable amount of public money is spent on cardiovascular diseases through such programs as Medicaid and Medicare. The incidence of these diseases could be significantly reduced through adequate blood pressure control in the populations receiving those benefits.)

(7) It would appear, therefore, that a rational division of a community's population could be made, such that most if not all people in the community could be covered by a blood pressure control program, either at their (or their spouse's) place of work or through a public or private health agency. Such a plan would require the cooperation of community physicians but would not necessarily require a major amount of their time, especially if new case finding were done in a gradual manner and the capability for handling new cases were gradually increased. The testing of such a plan remains to be done.

A number of issues regarding the blood pressure control model described above remain to be explored. Most importantly, monitoring of follow-up results over a much longer period of time is necessary. In addition, further studies would be useful on such subjects as (a) the optimal frequency of follow-up contacts, (b) a comparison of the long-term effectiveness of programs in different organizational locations, (c) the degree and type of training required for program personnel, (d) methods and techniques for disseminating blood pressure control systems to private and public organizations, and (e) a possible "ripple"' effect of programs, i.e., the gradual improvement of blood pressure control among people not involved in a program, because of interaction with people who are.

\section{ACKNOWLEDGMENTS}

The hypertension control system described in this article was developed and tested in close coordination with our own Program staff as well as our colleagues and staff members of the Hypertension Coordinating and Planning Council of Southeastern Michigan.

We would like to acknowledge and thank in particular the following people who made significant contributions to these blood pressure control procedures: (a) staff members of our own Program, including Revera Munce, R.N., Patricia A. Strauch, and Carol Kent; and (b) staff members of the Hypertension Coordinating and Planning Council, including Helen Barron, Catherine Lamb, R.N., Doris Newton, R.N., and Mary King.

We would also like to acknowledge the fine cooperation we received from the six organizations in 
which these procedures were tested, as well as from the attending physicians throughout southeastern Michigan.

This work was supported in large part through contracts with the Michigan Association for Regional Medical Programs, U.S. Department of Health, Education, and Welfare.

\section{REFERENCES}

1. Alderman, M. H., and Schoenbaum, E. E. Detection and treatment of hypertension at the work site. New Engl. J. Med. 293, 65-68 (1975).

2. Alderman, M. H., and Schoenbaum, E. E. Hypertension control among employed persons in New York City: 1973-75. Milbank Mem. Fund Quart. 53, 367-377 (1976).

3. Cardiovascular diseases in the United States-Facts and Figures. The American Heart Association, in cooperation with the National Heart Institute and the Heart Disease Control Program, Public Health Service, U. S. Department of Health, Education and Welfare, New York, 1965.

4. Charman, R. C. Hypertension management program in an industrial community. JAMA 227, 287-291 (1974).

5. Erfurt, J. C., and Foote, A. "Blood Pressure Control: A Manual of Procedures for Screening, Referral, and Long-Range Follow-Up." Institute of Labor and Industrial Relations, The University of Michigan-Wayne State University, Ann Arbor, Michigan, 1976.

6. Finnerty, F. A. New techniques for improving patient compliance, in "The Hypertension Handbook," pp. 117-124. Merck \& Co.. Inc., West Point, Pennsylvania, 1974.

7. Foote, A., and Erfurt, J. C. "Development and Dissemination of Model Systems for Hypertension Control in Organizational Settings." Institute of Labor and Industrial Relations, The University of Michigan-Wayne State University, Ann Arbor, Michigan, 1974.

8. Harburg, E., Erfurt, J. C., Chape, C., Hauenstein, L. S., Schull, W. J., and Shork, M. A. Socioecological stressor areas and black-white blood pressure: Detroit. J. Chron. Dis. 26, 595-611 (1973).

9. Inter-Society Commission for Heart Disease Resources. Guidelines for the detection, diagnosis and management of hypertensive populations, in "The Hypertension Handbook," pp. 209-218. Merck \& Co., Inc., West Point, Pennsylvania, 1974.

10. Kannel, W. B., Castelli, W. P., McNamara, P. M., McKee, P. A., and Feinleib, M. Role of blood pressure in the development of congestive heart failure. New Engl. J. Med. 287, 781-787 (1972).

11. Kannel, W. B., Wolf, P. A., Verter, J., and McNamara, P. M. Epidemiologic assessment of the role of blood pressure in stroke. JAMA 214, 301-310 (1970).

12. Lew. E. A. High blood pressure, other risk factors and longevity: The insurance viewpoint. Amer. J. Med. 55, 281-294 (1973).

13. Sackett. D. L., Gibson, E. S.. Taylor, D. W., Haynes, R. B., Hackett, B. C., Roberts, R. S., and Johnson, A. L. Randomised clinical trial of strategies for improving medication compliance in primary hypertension. Lancet, 1205-1207 (May, 1975).

14. Schoenberger, J. A., Stamler, J., Shekelle, R. B., and Shekclle, S. Current status of hypertension control in an industrial population. JAMA 222, 559-562 (1972).

15. Stamler, J., Stamler, R., Riedlinger, W. F., Algera, G., and Roberts, R. H. Hypertension screening of 1 million Americans: Community Hypertension Evaluation Clinic (CHEC) Program, 1973 through 1975. JAMA 235, 2299-2306 (1976).

16. Veterans Administration Cooperative Study Group on Antihypertensive Agents. Effects of treatment on morbidity in hypertension-Results in patients with diastolic blood pressures averaging 115 through $129 \mathrm{~mm} \mathrm{Hg}$. JAMA 202, 1028-1034 (1967).

17. Veterans Administration Cooperative Study Group on Antihypertensive Agents. Effects of treatment on morbidity in hypertension. II. Results in patients with diastolic blood pressure averaging 90 through $114 \mathrm{~mm} \mathrm{Hg.} \mathrm{JAMA} \mathrm{213,} 1143-1152$ (1970).

18. Wilber. J. A., and Barrow, J. G. Reducing elevated blood pressure-Experience found in a community. Minn. Med. 52, 1303-1305 (1969). 